\title{
Adaptação e validação de construto da Escala de Satisfação no Trabalho
}

\author{
Maria do Carmo Fernandes Martins ${ }^{1}$ \\ Gisele Emídio Santos
}

\begin{abstract}
Resumo
O objetivo deste estudo foi revisar, validar e apurar a fidedignidade da Escala de Satisfação no Trabalho, composta por 116 itens agrupados em 14 fatores válidos com fidedignidade insatisfatória. A revisão semântica manteve 113 itens, aplicados a 600 trabalhadores-estudantes, sendo 51\% mulheres, com nível de escolaridade média e superior, com idade média de 26 anos. Análises dos componentes principais e scree plot indicavam haver 7 a 12 componentes. A fatoração dos eixos principais com rotações Varimax e Promax reduziu a escala para 45 itens agrupados em seis fatores: "satisfação com suporte organizacional", "satisfação com utilidade social da organização e do trabalho", "satisfação com relacionamento afetivo no trabalho", "satisfação com reconhecimento profissional", "insatisfação com inadequação da chefia e falta de oportunidades" e "insatisfação com sobrecarga de trabalho" com alfas de 0,86 , $0,81,0,80,0,82,0,85$ e 0,81 . A estrutura do construto confirmou-se afetiva e multideterminada. Esta conclusão corroborou achados da área.

Palavras-Chave: Satisfação no trabalho; Escala de Medida de Satisfação no Trabalho; Validade; Fidedignidade; Análise fatorial.
\end{abstract}

\section{Adaptation and construct validation of Job Satisfaction Scale}

\begin{abstract}
The purpose of this study was revise semantic contents, validating and establishing the reliability of the Job Satisfaction Scale, formed by 116 items and grouped in 14 valid factors with unsatisfactory reliability. The semantic revision retained 113 applied to 600 workers-students, 51\% women, at nocturnal schools of medium and superior scholarship with average age of 26 years old. Analyses of the principal components and scree plot pointed 7 to 12 components. The principal axis factoring (Varimax and Promax rotation) reduced the scale to 45 items grouped in 6 factors: "satisfaction with organizational support", "satisfaction with social utility of the organization and of work", "satisfaction with affective relationship at work", "satisfaction with professional recognition", "insatisfaction with inadequacy of the working opportunities" and "insatisfaction with working overload". Cronbach's alfas were .86, $.81, .80, .82, .85$ and .81 . The job satisfaction construct was confirmed like affective and composed by two sets of factors. This conclusion corroborates the literature.

Keywords: Job satisfaction; Measurement Scale of Job Satisfaction; Construct validity; Reliability; Factor analysis.
\end{abstract}

\section{Introdução}

A satisfação do trabalhador com o trabalho que realiza tem sido estudada como uma das mais importantes variáveis conseqüentes da área de comportamento organizacional. Resultados de vários estudos têm identificado como preditores da satisfação no trabalho conteúdos mentais do indivíduo como crenças, valores, fatores disposicionais, moral e possibilidade de desenvolvimento no trabalho (Martins, no prelo).

Estudos mais recentes têm encontrado relações inversas entre satisfação e sofrimento no trabalho (Mendes \& Morrone, 2002) e entre satisfação e estresse ocupacional (Lesowitz, 1996). Suspeita-se que índices altos de insatisfação com o trabalho produzam altos níveis de sofrimento mental que podem levar o trabalhador a desenvolver certas síndromes ou mesmo algumas doenças relacionadas ao trabalho, como estresse ocupacional, doenças cardíacas e alérgicas e burnout definido por Maslach e Leiter (1997) como condição extrema com quadro de frustração ou fadiga, tensão emocional, esgotamento e falta de energia para lidar com a rotina profissional. Além disso, insatisfação tem estado associada negativamente com desempenho no trabalho e comportamentos pró-ativos (Meleiro \& Siqueira, 2005).

A importância do construto satisfação no trabalho para a área de comportamento organizacional remete os estudiosos a responderem ao desafio de avaliá-la de modo válido e preciso, conforme os princípios da psicometria. Para responder a este desafio, propôs-se como objetivo

\footnotetext{
${ }^{1}$ Endereço para correspondência:

Universidade Federal de Uberlândia - Faculdade de Psicologia

Av. Pará, 1.720 - bl. 2c - sala 15 - Umuarama - 38405-320 - Uberlândia - MG
} 
deste estudo a adaptação semântica, a atualização teórica e a revalidação fatorial da Escala de Satisfação no Trabalho de Martins (1984).

\section{Satisfação no trabalho: a evolução do conceito}

A satisfação do trabalhador diante do seu trabalho foi uma das mais estudadas atitudes no trabalho no século XX (O’Reilly III, 1990). Nas primeiras décadas daquele século, Taylor (1947) considerava que satisfação no trabalho "era uma atitude relativa à filosofia do trabalhador acerca da cooperação com a gerência de sua visão de seus próprios interesses" (Martins, 1984, p. 2). Para Taylor, aspectos como fadiga e o salário influenciavam a satisfação e produtividade.

Segundo Martins (no prelo), um grupo de pesquisadores de Hawthorne ampliou os fatores relacionados à satisfação, incluindo aspectos como pausas para descanso, importância dos grupos informais de trabalho, da supervisão recebida, a percepção que o trabalhador tinha do seu trabalho, dentre outros. Com isto demonstraram que o salário, ao contrário do que afirmava Taylor (1947), não era um aspecto tão importante da satisfação no trabalho.

Uma outra fase de estudos ocorreu durante a Segunda Guerra, quando o movimento das relações humanas deu ênfase ao crescimento mental do trabalhador como principal causa da satisfação. Para esse movimento, redefinir o trabalho, tornando-o mais desafiante e rico, mostrava a responsabilidade e o cuidado da empresa para com o trabalhador, o que aumentava a sua satisfação.

Revendo os estudos da área, pode-se perceber que a satisfação no trabalho tem sido definida quanto a seus aspectos causais mais relevantes e ao modo como eles podem ser combinados. Segundo Martins (1984), poucos autores preocuparam-se em definir satisfação no trabalho como conceito integrado que "reúna na mesma definição os mais variados aspectos relacionados na literatura ao conceito de satisfação no trabalho" (p. 8).

Locke (1976) definiu satisfação como "um estado emocional agradável ou positivo, que resulta de algum trabalho ou de experiências no trabalho", definição que tem, ainda hoje, o impacto mais importante para o conceito. Martins (1984), baseada na definição de Locke, afirmava que o homem usa de sua bagagem individual de crenças e valores para avaliar seu trabalho e essa avaliação resulta num estado emocional que, se for agradável, produz satisfação, e, se for desagradável, leva à insatisfação. Portanto, satisfação no trabalho é uma variável de natureza afetiva e se constitui num processo mental de avaliação das experiências no trabalho que resulta num estado agradável ou desagradável. Esse processo é influenciado pelos vários conteúdos mentais do indivíduo, como crenças, valores, fatores disposicionais, moral e possibilidade de desenvolvimento no trabalho (Levin \& Stocks, 1989; Staw \& Ross, 1985; Staw, Bell \& Clausen, 1986) e resulta numa tendência que orienta o comportamento. Neste sentido, é uma atitude (Fishbein \& Azjen, 1976).

Uma antiga classificação dos estudiosos de satisfação no trabalho dividia as teorias sobre satisfação em dois grupos (Martins, 1984). O primeiro deles reunia as explicações teóricas relacionadas às causas da satisfação; buscava especificar as variáveis relevantes e o modo como elas eram combinadas para determinar satisfação. O segundo, que reunia as teorias relativas ao conteúdo, tentava identificar necessidades ou valores específicos que compunham a satisfação. Todavia, essa classificação incluía como teorias de satisfação no trabalho várias criadas para explicar a motivação humana e não a satisfação no trabalho. Esta confusão prejudicou o esclarecimento do construto de satisfação no trabalho durante décadas. Assim sendo, neste artigo serão abordadas apenas as teorias diretamente ligadas à satisfação no trabalho e aquelas que tenham fornecido colaboração direta para a definição deste construto. Excluíram-se, portanto, as teorias de motivação propostas para explicar as necessidades humanas gerais.

Pode-se afirmar que a Teoria dos Dois Fatores de Herzberg, Mausner e Snyderman (1959) seja a primeira teoria proposta para explicar a satisfação com o trabalho. Ela pressupunha a existência de dois grupos de fatores, responsáveis, separadamente, pela satisfação no trabalho - os "motivadores", tais como o próprio trabalho, o desempenho, a promoção e o reconhecimento pelo trabalho executado -; e pela insatisfação no trabalho - os fatores "higiênicos", como supervisão, relações interpessoais no trabalho, política de organização e salário. A maior contribuição de Herzberg e cols. (1959) foi identificar a importância do crescimento psicológico como condição necessária para a satisfação no trabalho e demonstrar que este crescimento vem do próprio trabalho.

A teoria da expectância ou da expectativa de Vromm (1964) afirmava que variáveis situacionais e de personalidade produziam satisfação. Vroom definiu satisfação como reação antecipada a um resultado ou expectativa que o empregado espera conseguir. Locke (1976) criticou esta definição porque o modelo de Vroom só explicava os efeitos esperados. Para os inesperados, as reações afetivas dependiam da direção da expectativa. Se fosse positiva, seriam agradáveis; se fosse negativa, seriam desagradáveis, o que permite inferir que a expectativa funcionaria como variável moderadora do processo de avaliação.

Psico-USF, v. 11, n. 2, p. 195-205, jul./ der. 2006 
Outro modelo que explica satisfação no trabalho é resultante dos estudos de Lofquist e Davis (1969), Porter (1962) e Wofford (1971). Trata-se da teoria das necessidades de realização. Esse modelo postula que a satisfação no trabalho é determinada pelo grau no qual o trabalho atende às necessidades de realização do indivíduo, básicas para o seu bem-estar.

Já Wernimont (1972, em Locke, 1976) propôs um modelo mais complexo de explicação do construto, afirmando que variáveis externas como políticas da empresa, condições de trabalho, salário, dentre outros, causavam variáveis internas como sentimentos de satisfação ou insatisfação que, por sua vez, produziam variáveis conseqüentes como rotatividade, ausências e motivação no trabalho, dentre outras. Essa teoria afirmava ainda que as variáveis conseqüentes retroalimentavam as variáveis externas e faziam com que o sistema tivesse um funcionamento cíclico.

Em 1976, Locke, tentando dar um corpo mais integrado à literatura da área, propôs um outro modelo para explicar satisfação no trabalho. Ele postulou que esta era determinada por dois amplos fatores interrelacionados: os agentes, que reuniam características como o relacionamento entre os chefes, colegas e subordinados, o próprio self do indivíduo, as políticas da empresa e o estilo da gerência; e os eventos, que se caracterizam por aspectos tais como o trabalho em si, o pagamento, a política de promoção, o reconhecimento verbal e as condições de trabalho.

A teoria da eqüidade afirmava que a insatisfação era um efeito desagradável de cognições discordantes que constituía uma fonte de tensão a ser reduzida e, para isso, o indivíduo gastava energia (Landy, 1978, em Toulson \& Smith, 1994). Assim a satisfação, na teoria da eqüidade, era definida como ausência de insatisfação.

Ainda há outra teoria, a de Orpen (1981), que defende a influência dos valores na satisfação no trabalho, abordando satisfação, portanto, como uma atitude. Postula Orpen que, se os valores do indivíduo não estão sendo respeitados nas situações de trabalho, muito provavelmente os trabalhadores se sentirão insatisfeitos. Esta teoria tem sido reforçada por achados de estudos como os de Levin e Stocks (1989), Staw e Ross (1985) e Staw e cols. (1986).

Para Hackman e Oldham (1974), satisfação seria determinada por estados psicológicos críticos, causados por cinco características centrais do trabalho: variedade, identidade, significância, autonomia de tarefa e feedback recebido. Essa relação seria, segundo eles, moderada pela necessidade de crescimento do empregado.

Psico-USF, v. 11, n. 2, p. 195-205, jul./ dez. 2006
Em 1992, Quarstein, McAfee e Glassman postularam que satisfação era causada por características e ocorrências situacionais. As características são formadas por aspectos que os indivíduos avaliam antes de aceitar o trabalho, como pagamento e condições de trabalho, por exemplo. São mais estáveis. Já as ocorrências situacionais consistem nos aspectos do trabalho que não podem ser pré-avaliados e aparecem, quase sempre, de uma forma inesperada, depois que os indivíduos se encontram no trabalho. São transitórios.

Para um grupo de teóricos como Vroom (1964), Loffquist e Davis (1969), Orpen (1974), Landy (1978, em Toulson \& Smith, 1994), as reações afetivas dos indivíduos dependem da interação entre eles e seu meio. Para outro grupo, no qual estão Herzberg e cols. (1959) e Locke (1976), o indivíduo precisa satisfazer necessidades ou atender a valores para sentir-se satisfeito no trabalho.

Parece, então, haver duas vertentes sobre satisfação no trabalho, que defendem idéias diferentes. Em uma, as características do trabalho são os principais determinantes da satisfação e para a outra, o processamento das informações sociais é o aspecto mais relevante. Apesar de suas divergências, ambas enfatizam o papel dos aspectos situacionais que gerariam as atitudes e, portanto, a satisfação no trabalho (Salancik \& Pfeffer, 1977).

Segundo Staw e Ross (1985) e com os conceitos de processamento de informações sociais, as características do trabalho podem ser subjetivas e perceptualmente flexíveis, e as atitudes no trabalho podem ser determinadas tanto por fatores situacionais, quanto por aspectos disposicionais do indivíduo, relativamente estáveis através do tempo. Desse modo, mudanças no meio de trabalho poderiam afetar o indivíduo, dependendo de suas características disposicionais. Atitudes no trabalho, como satisfação, poderiam ser previstas por disposições afetivas do homem (Staw e cols., 1986), mas estariam influenciadas por aspectos ambientais.

Portanto, depois de seis décadas de estudos, ainda não há acordo na literatura sobre causas e componentes da satisfação no trabalho. Há, de um lado, uma tendência a investigar o aspecto disposicional do indivíduo (Davis-Blake \& Pfeffer, 1989; Gerhart, 1987; Staw, 1984) e do outro, uma tendência mais atual de definir o construto como sendo de natureza afetiva, atitudinal, e determinado por variáveis multiníveis individuais, grupais ou organizacionais - segundo afirmam Brief e Weiss (2002). Como se pode deduzir pela breve apresentação dos modelos teóricos, começou a consolidar-se a noção de que a empresa também era responsável pela satisfação do trabalhador. 
Talvez o principal problema da área ainda seja a medida de satisfação no trabalho. Melhor dizendo, talvez seja identificar um instrumento que contemple a definição do construto de satisfação como uma variável atitudinal, que envolve afeto do indivíduo sobre seu trabalho (Brief \& Weiss, 2002) e que depende de aspectos disposicionais e ambientais. Por isso, a seguir se abordará a questão da medida da satisfação no trabalho.

\section{Problemas relativos à mensuração da satisfação no trabalho}

As medidas de satisfação de trabalho identificadas na literatura, refletindo a inconclusão da área, possuem bases conceituais diversas, o que dificulta a comparação dos resultados de pesquisa. Portanto, quando se utilizam tais instrumentos, não se sabe o que está, de fato, sendo avaliado, já que as teorias que norteiam cada um deles são diferentes. Em alguns casos, os autores desses instrumentos sequer especificam a definição do construto que fundamentou sua construção.

As formas mais comuns de avaliar a satisfação no trabalho são as que utilizam escalas dos tipos Likert, que requerem respostas "sim", "não" e "em dúvida" ou respostas a escalas de maior número de pontos. Utilizam-se com menor freqüência os questionários com perguntas abertas, as entrevistas e a técnica dos incidentes críticos.

$\mathrm{O}$ mais antigo instrumento de medida de satisfação no trabalho publicado é o de Brayfield e Rothe (1951), unifatorial, que se propõe a avaliar a satisfação geral no trabalho por meio de dezoito itens e que talvez tenha sido o mais utilizado e o que provocou maior impacto na literatura da área.

No Brasil, nas décadas de 70 e 80 , alguns instrumentos foram construídos e validados fatorialmente (Martins, 1984; Nogueira \& Pasquali, 1981; Siqueira, 1978). Todos utilizaram análise fatorial e demonstravam a multidimensionalidade do construto. O instrumento de Martins (1984) confirmou a estrutura bifatorial do construto: os fatores de satisfação apareceram claramente separados dos que compõem a insatisfação, confirmando a Teoria de Herzberg e cols. (1959).

Martins (1984) identificou fatorialmente que o construto reunia quatorze aspectos teóricos: aspectos da chefia, riscos de trabalho, suficiência de salário, estabilidade do emprego, fadiga, carga de trabalho e de responsabilidade, reconhecimento do trabalho realizado, estabilidade da empresa, aspectos físicos do trabalho, relacionamento com os colegas, contribuição da empresa para a melhoria da sociedade, interesse pelo trabalho e pela empresa, utilidade da empresa para a sociedade e para o empregado e promoção por mérito. Estes foram agrupados em quatro fatores amplos, com base em seu conteúdo semântico: "trabalho em si", que reunia carga de trabalho, responsabilidade e interesse pelo trabalho e pela empresa; "condições de trabalho", que reuniu riscos, fadiga, aspectos físicos e relacionamento com colegas; "organização", que agrupava estabilidade do emprego, reconhecimento pelo trabalho realizado, estabilidade da empresa, contribuição da empresa para a sociedade e utilidade da empresa para a sociedade e para o empregado; e "benefícios do trabalhador", que reuniu aspectos da chefia e salário. Essa estrutura confirmou, com pequenas variações, a Teoria de Herzberg e cols. (1959): os agrupamentos "trabalho em si" e "condições de trabalho" referiam-se à satisfação e "organização" e "benefícios do trabalhador", à insatisfação. Todavia, esse instrumento possuía índices frágeis de fidedignidade, sete deles com alfas em torno de 0,70.

Mais recentemente, Siqueira (1995) construiu e validou um instrumento de medida de satisfação no trabalho. Todavia, a literatura anteriormente mencionada permite supor que satisfação no trabalho seja um construto muito mais rico conceitualmente. Essa riqueza conceitual não estava representada em nenhum instrumento brasileiro recentemente publicado. A Escala de Satisfação no Trabalho de Martins (1984) representava essa amplitude conceitual do construto, mas apresentava problemas: estava desatualizada teórica e culturalmente, possuía fragilidade psicométrica relativa à fidedignidade e carecia de uma atualização semântica.

Considerando-se que os procedimentos para corrigir esses problemas poderiam modificar suas características psicométricas, ficou clara a necessidade de novo teste da validade de construto, por meio da análise fatorial, e de nova verificação dos índices de fidedignidade. Por isso, definiu-se como objetivo deste estudo verificar a adequação semântica, reavaliar a validade de construto por meio da análise fatorial e testar os índices de fidedignidade da Escala de Satisfação no Trabalho (Martins, 1984), o que se passará a relatar.

\section{Método}

\section{Procedimentos de adaptação da escala}

A Escala de Satisfação no Trabalho de Martins (1984) era composta por 116 itens distribuídos em 14 fatores. Estudos sobre satisfação no trabalho evoluíram muito nos últimos 20 anos que se passaram depois de sua construção. Por isso, foi preciso rever os conteúdos 
e o formato da escala. Seus itens foram adaptados para referir-se somente a estados afetivos resultantes de avaliação de aspectos do trabalho. Dessa adaptação semântica e de conteúdo, resultaram 113 itens. A avaliação semântica foi feita para verificar a clareza dos itens; sua compreensão foi testada com alguns participantes representantes do menor nível de escolaridade da amostra com a qual se pretendia trabalhar, correspondente ao ensino médio. Foram descartados dois itens, porque não tinham utilidade para a definição do construto, e modificada a redação de outros para beneficiar sua clareza semântica.

\section{Procedimentos de coleta dos dados}

O projeto foi devidamente aprovado pelo Comitê de Ética em Pesquisa da Universidade Federal de Uberlândia.

$O$ instrumento foi aplicado a trabalhadores formais contatados em escolas noturnas de segundo grau, em faculdades privadas e em uma universidade pública da cidade de Uberlândia. Este procedimento foi adotado porque o estudo demandava participantes que pudessem responder sozinhos à escala, sendo capazes de ler e compreender pequenos textos.

A aplicadora dirigia-se às salas de aula, solicitava licença do professor, explicava-lhe os objetivos do trabalho e pedia sua autorização para falar com os alunos. A eles, explicava os objetivos do estudo, esclarecia o anonimato de suas respostas, esclarecendo que os questionários não eram identificados, e solicitava autorização formal para colaborar, pedindo-lhes que assinassem um termo de consentimento no qual constava o compromisso de sigilo por parte dos pesquisadores e a garantia de que nenhum prejuízo lhes adviria de suas respostas.

Foi-lhes explicado que as conclusões do estudo resultariam das respostas do grupo e que nenhum questionário seria analisado individualmente. Colhidos os termos de consentimento, a aplicadora lia as instruções, esclarecia as dúvidas, distribuía as escalas, aguardava que os participantes respondessem e recolhia os questionários respondidos.

\section{Procedimentos de análise dos dados}

As respostas dos participantes foram codificadas numa planilha do software SPSS (Statistical Package of The Social Sciences) e submetidas a análises estatísticas descritivas, à análise fatorial e ao cálculo do alfa de Cronbach.

Os dados foram examinados quanto à normalidade, colinearidade e distribuição de outliers. A fatorabilidade da amostra foi testada pelo índice de Kaiser-Meyer-Olkin e pelo teste de esfericidade de Psico-USF, v. 11, n. 2, p. 195-205, jul./dez. 2006
Bartlett, conforme recomendação de Tabachnick e Fidell (2001). Depois disso, os dados foram submetidos a análises dos componentes principais (PC) e à fatoração dos eixos principais (PAF). A fidedignidade dos fatores foi estimada pelo cálculo dos alfas de Cronbach.

\section{Participantes}

Participaram do estudo 600 trabalhadores, pertencentes a mais de 50 cargos diferentes, de todos os níveis organizacionais. Havia profissionais ocupantes de cargos muito variados como teleatendentes e diretores de empresas. Os participantes possuíam tempo médio de experiência profissional de 55 meses.

Quanto ao nível de escolaridade, a maioria (98\%) possuía nível universitário, era oriunda de 20 diferentes cursos das três áreas do conhecimento: ciências humanas (como Psicologia, Filosofia, Pedagogia), biológicas (como Medicina, Biologia, Enfermagem) e exatas (como Engenharia Civil, Mecânica e Elétrica, Computação, Matemática). Apenas 2\% tinham segundo grau incompleto e eram alunos de uma escola particular de ensino médio.

O conjunto dos participantes era bastante jovem: a média de idade foi de 26 anos ( $\mathrm{DP}=7$ anos); $68 \%$ do total eram solteiros e somente $28 \%$ eram casados. Mulheres constituíram a maioria da amostra $(51 \%)$ e os que se declaravam brancos somavam $82 \%$ dos participantes. Os autodeclarados pardos, mulatos e negros somavam $18 \%$.

\section{Resultados}

\section{Validação fatorial e fidedignidade}

Todos os pressupostos da análise fatorial foram atendidos. Os resultados do teste de Kaiser-Meyer-Olkin $(\mathrm{KMO}=0,91)$ considerado excelente (Tabachnick \& Fidell, 2001) e do teste de esfericidade de Bartlett $\left(\chi^{2}=\right.$ $29247,52 ; p<0,001)$ demonstraram a adequação da amostra para análise fatorial.

Para estimar o número de componentes, foi feita a análise dos principais, que identificou, inicialmente, 12 componentes com valores próprios iguais a ou maiores que 1,5 e cargas fatoriais iguais a ou maiores que 0,30, que explicavam $44 \%$ da variância total. Todavia, o scree plot demonstrou a existência de, no máximo, sete componentes.

Os dados foram posteriormente submetidos à fatoração dos eixos principais (PAF) porque havia base teórica considerável acerca do construto (Pasquali, 2006; Tabachnick \& Fidell, 2001). A matriz de correlação entre os fatores mostrou que alguns deles correlacionavam-se entre si, enquanto outros não. Apesar disso, foi feita uma primeira tentativa de rotação Varimax. 
A análise semântica dos conteúdos dos itens componentes de cada um dos 12 fatores mostrou dois conjuntos conceituais distintos, um relativo à satisfação e outro à insatisfação no trabalho. Todavia, havia correlações entre alguns componentes que não poderiam ser desconsideradas. Esse fato apontava para a possível existência de dois blocos de conteúdos semanticamente distintos.

Uma segunda análise com os mesmos métodos de extração e com a mesma rotação Varimax foi realizada com os itens retidos na análise anterior, forçando-se dois fatores. $\mathrm{Na}$ solução resultante, os dois fatores distinguiam-se quanto aos conteúdos de seus itens. Um deles reuniu os de conteúdos relacionados à satisfação e o outro agrupou itens referentes à insatisfação. A correlação de Pearson calculada (baixa, negativa e não- significante) entre os dois fatores indicou independência entre eles. Todavia, esses dois amplos fatores reuniam itens de fatores resultantes da primeira análise correlacionados entre si.

Por isso, decidiu-se proceder a duas outras análises fatoriais com método de extração PAF e rotação Promax, uma para o conjunto de itens reunidos no primeiro fator, cujos conteúdos eram referentes à satisfação, e outra para o conjunto de itens do segundo fator, referentes à insatisfação. Os mesmos critérios de seleção de fatores e de itens foram utilizados.

Da análise com os itens componentes do primeiro fator resultaram cinco fatores, que explicaram aproximadamente $53 \%$ da variância total da satisfação no trabalho (ver Tabela 1 ).

Tabela 1 - Características psicométricas dos fatores de satisfação no trabalho

\begin{tabular}{|c|c|c|c|}
\hline Fatores & Item & Carga & Comunalidade \\
\hline \multirow{9}{*}{$\begin{array}{l}\text { 1: satisfação com o } \\
\text { reconhecimento } \\
\text { profissional }\end{array}$} & 5 & 0,83 & 0,64 \\
\hline & 6 & 0,53 & 0,60 \\
\hline & 9 & 0,43 & 0,58 \\
\hline & 13 & 0,57 & 0,55 \\
\hline & 14 & 0,37 & 0,68 \\
\hline & 15 & 0,68 & 0,67 \\
\hline & 23 & 0,40 & 0,67 \\
\hline & 24 & 0,43 & 0,68 \\
\hline & 38 & 0,34 & 0,61 \\
\hline \multicolumn{3}{|l|}{$\alpha=0,82$} & variância explicada $=35 \%$ \\
\hline \multirow{4}{*}{$\begin{array}{l}\text { 2: satisfação com a } \\
\text { utilidade social da } \\
\text { organização e do trabalho }\end{array}$} & 65 & 0,40 & 0,61 \\
\hline & 68 & 0,79 & 0,67 \\
\hline & 69 & 0,76 & 0,74 \\
\hline & 87 & 0,62 & 0,70 \\
\hline \multirow[t]{4}{*}{$\alpha=0,81$} & & & variância explicada $=7 \%$ \\
\hline & 40 & 0,61 & 0,69 \\
\hline & 48 & 0,72 & 0,60 \\
\hline & 51 & 0,68 & 0,63 \\
\hline \multirow{5}{*}{$\begin{array}{l}\text { 3: satisfação com o suporte } \\
\text { organizacional }\end{array}$} & 57 & 0,46 & 0,65 \\
\hline & 70 & 0,54 & 0,65 \\
\hline & 78 & 0,87 & 070 \\
\hline & 79 & 0,57 & 0,68 \\
\hline & 101 & 0,34 & 0,60 \\
\hline \multirow[t]{3}{*}{$\alpha=0,86$} & & & variância explicada $=4 \%$ \\
\hline & 85 & 0,31 & 0,67 \\
\hline & 103 & 0,37 & 0,55 \\
\hline \multirow{4}{*}{$\begin{array}{l}\text { 4: satisfação com o } \\
\text { relacionamento afetivo no } \\
\text { trabalho }\end{array}$} & 104 & 0,37 & 0,72 \\
\hline & 109 & 0,33 & 0,61 \\
\hline & 112 & 0,67 & 0,72 \\
\hline & 113 & 0,79 & 070 \\
\hline$\alpha=0,80$ & & & variância explicada $=4 \%$ \\
\hline
\end{tabular}


$\mathrm{O}$ primeiro fator, "satisfação com o reconhecimento profissional", reuniu nove itens e teve alfa de 0,82. Agrupou itens como "sou importante profissionalmente" e "meus colegas reconhecem a minha capacidade no trabalho". Explicou 35\% do total da variância constatada. $\mathrm{O}$ fator dois, com quatro itens, reuniu conteúdos referentes à "satisfação com a utilidade social da organização e do trabalho" como: "meu trabalho ajuda a melhorar a sociedade" e "esta empresa faz coisas úteis para a sociedade". Revelou alfa de 0,81 e explicou $7 \%$ da variância total.

O terceiro deles foi responsável pela explicação de $4 \%$ da variância total e reuniu oito itens com conteúdos referentes à "satisfação com o suporte organizacional", como "meu chefe incentiva seus subordinados" e "posso confiar no meu chefe". Apresentou alfa de 0,86 . O quarto fator, "satisfação com relacionamento afetivo no trabalho", reuniu seis itens e teve alfa de 0,80. Agrupou itens como "gosto dos meus colegas de trabalho" e "vejo o meu chefe como amigo" e também explicou $4 \%$ da variância. $O$ quinto fator explicava $3 \%$ da variância, revelou alfa de 0,68 e reuniu três itens. Além do índice de fidedignidade pouco satisfatório, o conjunto dos itens foi semanticamente ininterpretável. Estas características levaram a descartá-lo. Da análise fatorial com os itens referentes à insatisfação, surgiram dois fatores (ver Tabela 2) que explicaram 44\% da variância total do construto de insatisfação: um reuniu conteúdos relativos à "insatisfação com a falta de suporte psicossocial", composto por itens como "meu chefe gosta de corrigir a gente só para chatear" e "falta ajuda do meu chefe quando preciso". Esse fator explicou 30\% da variância da insatisfação. $\mathrm{O}$ outro foi identificado como "insatisfação com a sobrecarga de trabalho", explicou $14 \%$ da variância total de insatisfação, manteve-se com oito itens e alfa de 0,81 . Reuniu itens como "fico esgotado de tanto trabalhar" e "trabalho mais do que posso".

Assim, a Escala de Satisfação com o Trabalho ficou composta por 45 itens, reunidos em seis fatores (ver Tabelas 1 e 2) denominados: "satisfação com o suporte organizacional", "satisfação com a utilidade social da organização e do trabalho", "satisfação com relacionamento afetivo no trabalho", "satisfação com o reconhecimento profissional", "insatisfação com a inadequação da chefia e com falta de oportunidades" e "insatisfação com a sobrecarga de trabalho", todos com excelentes índices de fidedignidade (ver Tabelas 1 e 2).

Tabela 2 - Características psicométricas dos fatores de insatisfação no trabalho

\begin{tabular}{lccc}
\hline Fatores & Item & Carga fatorial & Comunalidade \\
\hline 1: insatisfação com a falta & 67 & 0,59 & 0,60 \\
de suporte social & 71 & 0,46 & 0,59 \\
& 81 & 0,55 & 0,59 \\
& 84 & 0,60 & 0,59 \\
& 93 & 0,51 & 0,60 \\
& 95 & 0,64 & 0,63 \\
2: insatisfação com a & 96 & 0,56 & 0,59 \\
sobrecarga de trabalho & 100 & 0,58 & 0,61 \\
& 107 & 0,66 & 0,61 \\
& 110 & 0,61 & 0,60 \\
$\alpha=0,81$ & & & variância explicada= 30\% \\
& 2 & 0,76 & 0,57 \\
& 26 & 0,60 & 0,64 \\
& 30 & 0,80 & 0,65 \\
& 42 & 0,70 & 0,61 \\
& 61 & 0,30 & 0,59 \\
& 75 & 0,30 & 060 \\
& 80 & 0,68 & 0,64 \\
& 86 & 0,82 & 0,67 \\
& & & variância explicada= \\
\end{tabular}




\section{Discussão}

Depois de 20 anos de construída, a Escala de Satisfação no Trabalho apresentou uma estrutura fatorial simplificada em relação ao instrumento de Martins (1984), mantendo seis fatores dos quatorze do estudo original. Os índices de fidedignidade da escala melhoraram substancialmente, revelando-se todos maiores que 0,80, classificados por Pasquali (2001) como excelentes.

A matriz de correlação entre os fatores havia revelado valores medianos que não poderiam ser considerados como ausência de correlação. Alguns valores dessa matriz, entretanto, eram bastante baixos e negativos e pareciam revelar dois grupos de fatores. Esses resultados, considerados à luz da Teoria dos Dois Fatores de Herzberg e cols. (1959), pareciam apontar estruturas distintas para satisfação e insatisfação. Isso levou as autoras a tentarem uma rotação Varimax. Os fatores resultantes separaram os itens referentes à satisfação num fator e à insatisfação em outro, o que permitiu inferir que haveria mesmo dois amplos agrupamentos, um relativo à satisfação e outro, à insatisfação.

Por isso, optou-se por analisar o conjunto de itens de cada fator separadamente, utilizando método de extração PAF e de rotação Promax, este indicado para conjuntos de dados com essas características (Nunnaly \& Bernstein, 1995). Segundo esses autores, a rotação Promax, é oblíqua; todavia, pressupõe fatores "conceitualmente independentes, mas correlacionados" medianamente (Nunnaly \& Bernstein, 1995, p. 560). Confirmando a postura de Nunnaly e Bernstein, Hair, Anderson, Tatham e Black (2005) afirmam que a rotação Promax é de cálculo mais rápido que a Oblimin e a mais adequada para grandes conjuntos de dados. Portanto as opções metodológicas pareceram adequadas.

Os resultados obtidos permitiram concluir que os procedimentos de análise adotados neste estudo, levaram a identificar adequadamente a estrutura empírica de um construto com dois contínuos distintos, um de satisfação e outro de insatisfação. Esses dois contínuos estão compostos por fatores correlacionados entre si; todavia, essas correlações possuem valores medianos.

Apesar de todo o cuidado com a escolha dos métodos de extração e de rotação, vale ressaltar aqui que Nunnaly e Bernstein (1995) afirmam que "as soluções oblíquas e ortogonais conduzem, provavelmente, às mesmas conclusões" (p. 608). Isso foi confirmado por uma análise fatorial com rotação Promax, não relatada neste texto, na qual os mesmos fatores foram identificados a partir do banco de dados geral, sem que fossem feitas análises em separado. Há que se destacar, ainda, que a solução fatorial identificada permitiu explicar parte considerável da variância das duas dimensões do construto de satisfação no trabalho.

A estrutura do construto confirmou-se como afetiva e multideterminada, o que corrobora estudos empíricos anteriores como os de Siqueira (1978), Nogueira e Pasquali (1981), Martins (1984), Lesowitz (1996), Brief e Weiss (2002), baseados no conceito de satisfação no trabalho mais freqüentemente utilizado na área nas últimas quatro décadas: "um estado emocional agradável ou positivo, que resulta da avaliação de algum trabalho ou de experiências no trabalho" (Locke, 1976, p. 1300).

A identificação de dois blocos de fatores, com pequena correlação entre si, mas formados por fatores significativamente correlacionados, permite afirmar que os resultados obtidos neste estudo, confirmam a clássica Teoria dos Dois Fatores de Herzberg e cols. (1959), como fez o estudo de (Martins, 1984). Essa autora, partindo de uma listagem de 405 itens, que representavam a amplitude da definição do construto, utilizou método de extração dos componentes principais e rotação Varimax em três séries consecutivas de análises com o objetivo de "redução da ordem da matriz de intercorrelações” (p. 56). Chegou a 139 itens, que foram submetidos à quarta análise, com o mesmo método de extração e rotação Oblimin, a fim, segundo a autora, "de permitir fatores com itens de cargas fatoriais mais acentuadas [...] permitindo que os vetores fatoriais atravessassem os itens em seus maiores agrupamentos naturais". (p. 56). Da última rodada de análise, identificou 14 fatores formados por 116 itens e, com base em seus conteúdos, reuniu-os no que denominou "quatro fatores amplos": trabalho em si, condições de trabalho, organização e benefícios do trabalhador.

A Escala de Satisfação no Trabalho descrita neste relato constituiu-se numa adaptação do instrumento de Martins (1984). Foi, além disso, revalidada e teve seus índices de fidedignidade calculados. A estrutura fatorial identificada neste estudo ficou mais condensada do que aquela da escala original. Dos seis fatores mantidos, quatro compõem o construto de satisfação e dois, o de insatisfação no trabalho.

$\mathrm{Na}$ estrutura identificada por Martins (1984), o fator "carga de trabalho" reuniu itens semelhantes aos que compõem o fator denominado neste relato "insatisfação com sobrecarga de trabalho"; os itens componentes do fator "aspectos da chefia" de Martins (1984) dividiram-se, formando dois novos fatores: 
"satisfação com o suporte organizacional" e "insatisfação com a inadequação da chefia e com a falta de oportunidades", este último formado por itens de cargas negativas. O fator "contribuição da empresa para a sociedade e utilidade da empresa para a sociedade e para o empregado", do estudo de 1984, teve composição semelhante ao fator "satisfação com a utilidade social da organização e do trabalho".

"Relacionamento com colegas", um dos quatorze fatores de Martins, é bastante semelhante ao fator denominado "satisfação com relacionamento afetivo no trabalho" e, finalmente, "reconhecimento pelo trabalho realizado" teve composição bastante semelhante ao fator denominado "satisfação com o reconhecimento profissional". É preciso destacar que houve significativa redução do número de itens por fator.

Todavia, foi confirmada a estrutura de dois contínuos distintos que formam o construto da satisfação no trabalho encontrada por Martins (1984), há 20 anos, nessa mesma região geopolítica. A essas duas dimensões, Herzberg e cols. (1959) chamaram fatores "motivadores" e "higiênicos".

Apesar de polêmica na literatura, na qual parte dos estudos a confirma e parte a rejeita, a Teoria dos Dois Fatores de Herzberg e cols. (1959) pôde ser confirmada neste segundo teste feito no Brasil, embora o número de fatores componentes de cada dimensão seja bastante menor. Isso talvez se deva a mudanças culturais decorrentes do desenvolvimento do Brasil nestes vinte anos, ou mesmo às culturas mais flexíveis das organizações envolvidas neste estudo, distintas daquela abrangida pelo primeiro estudo de Martins (1984), que era caracterizada por valores e hierarquia bastante rígidos; os dados do estudo de Martins, (1984) foram coletados numa instituição militar. Esta estrutura encontrada pode ter sido também conseqüência do avanço científico dos estudos acerca do construto de satisfação no trabalho, que levou as autoras a focalizarem o conteúdo dos itens adaptados em estados afetivos relativos ao trabalho.

Como exposto anteriormente, os estudos sobre satisfação no trabalho têm demonstrado que esta é uma variável inequivocamente afetiva, de natureza atitudinal, derivada da interação entre características do trabalho e características pessoais dos trabalhadores.

As escalas resultantes podem ser consideradas psicometricamente válidas e fidedignas; adequadas, portanto, para serem utilizadas como ferramentas para diagnóstico da satisfação no trabalho, já que podem medir ambas as dimensões do construto com segurança, apesar de explicarem apenas parte da variância total da satisfação e da insatisfação no trabalho. Ainda assim, considerando-se a complexidade do construto estudado, a escala resultante desta validação pode ser útil para futuras investigações e diagnósticos.

Estudos têm mostrado a importância das dimensões do construto de satisfação no trabalho como antecedentes e como conseqüentes de outras variáveis de múltiplos níveis (Albuquerque, 2003; Antloga, 2003; Machado, 1997; Mendes, 1999; Morrone, 2001; Mota, 2002; Paschoal, 2003; Pereira, 2003; Resende, 2003; Silva, 1999; Stacciarini, 1999). Ferramentas como a que resultou deste estudo, de características psicométricas adequadas, apesar de explicarem parte do construto, podem ser bastante úteis em estudos futuros.

Como agenda de pesquisa, sugerem-se novos testes da estrutura empírica do construto de satisfação de modo a buscar confirmar sua estrutura bidimensional e a composição dessas duas dimensões. Sugerem-se ainda estudos discriminantes entre os construtos de satisfação no trabalho e outros que surgiram há menos tempo na literatura, como envolvimento com o trabalho, centralidade do trabalho e comprometimento organizacional afetivo.

Além disso, também seria útil investigar como satisfação no trabalho, em ambos os contínuos, se comporta como antecedente de outras variáveis. Particularmente importante para a área, seria tentar identificar o poder de predição da satisfação no trabalho sobre resultados da organização e a saúde dos trabalhadores, já que estudos sobre esta relação apresentam resultados ainda bastante inconclusivos.

\section{Referências}

Albuquerque, A. S. (2003). Bem-estar subjetivo e sua relação com personalidade, coping, suporte social, satisfação conjugal e satisfação no trabalho (Tese de Doutorado). Brasília: Universidade de Brasilia - Instituto de Psicologia.

Antloga, C. S. X. (2003). Estilo de contato da organização com o funcionário e prazer e sofrimento no trabalho: estudo de caso em uma empresa de material de construção no Distrito Federal (Dissertação de Mestrado). Brasília: Universidade de Brasília - Instituto de Psicologia.

Brayfield, A. H. \& Rothe, H. F. (1951). An index of job satisfaction. Journal of Applied Psychology, 35, 307-311.

Brief, A. P. \& Weiss, H. M. (2002). Organizational behavior: Affect in the workplace. Annual Review of Psychology, 53, 279-307

Davis-Blake, A. \& Pfeffer, J. (1989) Just a mirage: The search for dispositional effects in organizational research. Academy Management Journal, 14, 385-400. 
Fishbein, M. \& Azjen, I. (1976). Belief, attitude, intention and behavior: An introduction to theory and research. London: Addison-Wesley.

Gerhart, B. (1987). How important are dispositional factors as determinants of job satisfaction? Implications for job design \& other personnel programs. Journal of Applied Psychology, 72, 366-373.

Hackman, J. R. \& Oldham, G. R. (1974). Motivation through the design of work: Test of a theory. SOM: Yale University.

Hair, J. F., Anderson, R. E., Tatham, R. L. \& Black, W. C. (2005). Análise multivariada de dados. Porto Alegre: Bookman.

Herzberg, F., Mausner, B. \& Snyderman, B. (1959). The motivation to work. New York: Wiley.

Lesowitz, T. E. (1996) Job-related estresse, organizational estresse, and nonworking estresse as predictors of job satisfaction (Tese de Doutorado). Chicago: DePaul University.

Levin, I. \& Stocks, J. P. (1989). Dispositional approach to the job satisfaction: Role of negative affectivity. Journal of Applied Psychology, 74(5), 752-758.

Locke, E. A. (1976). The nature and causes of job satisfaction. Em M. D. Dunnette (Org.). Handbook of industrial and organizational psychology (pp. 1297-1350). Chicago: Rand McNally College Publishing Company.

Loffquist, L. H. \& Davis, R. V. (1969). Adjustment to work. New York: Appleton Century Crofts.

Machado, S. S. (1997). Fatores relacionados ao eestressee ocupacional em ambientes de risco (Dissertação de Mestrado). Brasília: Universidade de Brasília Instituto de Psicologia.

Martins, M. C. F. (1984) Satisfação no trabalho: elaboração de instrumento e variáveis que afetam a satisfação (Dissertação de Mestrado). Brasília: Universidade de Brasília Instituto de Psicologia.

Martins, M. C. F. (no prelo). Satisfação no trabalho: uma revisão de décadas de estudos. Revista da Sociedade de Psicologia do Triângulo Mineiro.

Maslach, C. \& Leiter, M. P. (1997). The truth about burnout. San Francisco: Jossey-Bass.

Meleiro, A. R. \& Siqueira, M. M. M. (2005). Os impactos do suporte do supervisor e de estilos de liderança sobre bem-estar no trabalho. XXIX ENANPAD textos completos. Brasília. CD-ROM, EOR-B 992, 15 p.

Mendes, A. M. (1999). Valores e vivências de prazersofrimento no contexto organizacional (Tese de Doutorado). Brasilia: Universidade de Brasília - Instituto de Psicologia.
Mendes, A. M. \& Morrone, C. F. (2002). Vivências de prazer-sofrimento e saúde psíquica no trabalho: trajetória conceitual e empírica. Em A. M. Mendes, L. O. Borges \& M. C. Ferreira (Orgs.). Trabalho em transição, saúde em risco (pp. 26-42). Brasília: Editora UnB.

Morrone, C. F. (2001) "Só para não ficar desempregado." Ressignificando o sofrimento psíquico no trabalho: estudo com trabalhadores em atividades informais (Dissertação de Mestrado). Brasília: Universidade de Brasília Instituto de Psicologia.

Mota, L. M. O. (2002) Treinamento e prazer-sofrimento psíquico no trabalho (Dissertação de Mestrado). Brasília: Universidade de Brasilia - Instituto de Psicologia.

Nogueira, P. R. \& Pasquali, L. (1981). Satisfação no trabalho - construção de um instrumento. Arquivos Brasileiros de Psicologia, 33, 3-18.

Nunnaly, J. C. \& Bernstein, I. J. (1995). Teoría Psicométrica. Buenos Aires: McGraw Hill.

O’Reilly III, C. A. (1990). Organizational behavior: Where we've been, where we're going. Annual Review of Psychology, 2, 427-58.

Orpen, C. (1974). A cognitive consistency approach to job satisfaction. Psychological Reports, 36, 239-245.

Orpen, C. (1981). Effect of flexible working hours on employee satisfaction and performance: A field experiment. Journal of Applied Psychology, 66(1), 113.

Paschoal, T. (2003) Relação dos valores do trabalho e da interferência familia-trabalho com estresse ocupacional (Dissertação de Mestrado). Brasília: Universidade de Brasília - Instituto de Psicologia.

Pasquali, L. (2001). Psicometria. São Paulo: Casa do Psicólogo.

Pasquali, L. (2006). Análise fatorial: um manual teórico-prático. Brasília, DF: Laboratório de Pesquisa em Avaliação e Medida.

Pereira, J. A. S. (2003). Vivências de prazer e sofrimento na atividade gerencial em empresa estratégica: 0 impacto dos valores (Dissertação de Mestrado). Brasília: Universidade de Brasília - Instituto de Psicologia.

Porter, L. W. (1962). Job attitudes in management: Its perceived deficiencies in need fulfillment as a function of job level. Journal of Applied Psychology, 46, 375-384.

Quarstein, V. A., McAfee, R. B. \& Glassman, M. (1992). The situational occurrences theory of job satisfaction. Human Relations, 45(8), 859-873.

Resende, S. (2003). Vivências de prazer e sofrimento no trabalho bancário: o impacto dos valores individuais e variáveis

Psico-USF, v. 11, n. 2, p. 195-205, jul./dez. 2006 
demográficas (Dissertação de Mestrado). Brasília: Universidade de Brasília - Instituto de Psicologia.

Salancick, G. R. \& Pfeffer, J. (1977). The bases and use of power in organizational decision making: The case of the university. Administrative Science Quartely, 19, 453473.

Silva, A. V. (1999). Comportamento de motoristas de ônibus: itinerário urbano, estressores ocupacionais e estratégias de enfrentamento (Dissertação de Mestrado). Brasília: Universidade de Brasília - Instituto de Psicologia.

Siqueira, M. M. M. (1978). Satisfação no trabalho (Dissertação de Mestrado). Brasília: Universidade de Brasília - Instituto de Psicologia.

Siqueira, M. M. M. (1995). Antecedentes de comportamentos de cidadania organizacional: análise de um modelo pós-cognitivo (Tese de Doutorado). Brasília: Universidade de Brasília - Instituto de Psicologia.

Stacciarini. J. M. R. (1999). Estresse ocupacional, estilos de pensamento e coping na satisfação, mal-estar físico e psicológico dos enfermeiros (Tese de Doutorado). Brasília: Universidade de Brasília - Instituto de Psicologia.

Staw, B. M. (1984). Organizational behavior: A review and reformulation of the field's outcome variables. Annual Review of Psychology, 35, 627-666.
Staw, B. M. \& Ross, J. (1985). Stability in the midst of change: A dispositional approach to job attitudes. Journal of Applied Psychology, 70, 469-480.

Staw, B. M., Bell, N. E. \& Clausen, J. A. (1986). The dispositional approach to job attitudes: A Lifetime Longitudinal Test. Administrative Science Quarterly, 31, 56-77.

Tabachnick, B. \& Fidell, L. (2001). Using multivariate statistics. New York: Harper Collins.

Taylor, F. (1947). Principles of scientific management. New York: Harper Brothers.

Toulson, P. \& Smith, M. (1994). The relationship between organizational climate and employee perceptions of personnel management practices. Public Personnel Management, 23(3), 453-468.

Vromm, V. H. (1964). Work \& motivation. New York: Wiley \& Sons.

Wofford, J. C. (1971). The motivational bases of job satisfaction. Personnel Psychology, 24, 501-518.

Recebido em outubro de 2005 Reformulado em janeiro de 2006 Aprovado em fevereiro de 2006

Sobre as autoras:

Maria do Carmo Fernandes Martins é doutora em Psicologia pela Universidade de Brasília, professora da Universidade Federal de Uberlândia e Coordenadora do Programa de Pós-Graduação em Psicologia. Atua na área de Comportamento Organizacional, investigando temas como clima, poder e comprometimento organizacionais, avaliação de treinamento, efetividade e satisfação no trabalho. É autora de várias escalas de medida na área, de artigos e capítulos de livros.

Gisele Emídio Santos é aluna de Graduação em Psicologia da Universidade Federal de Uberlândia e foi bolsista de PIBIC/CNPQ. Possui interesse e desenvolve pesquisas em Comportamento Organizacional, tendo vários trabalhos apresentados em congressos em co-autoria com seus orientadores. 
